\title{
Effects of Microwave Pretreatment of Apple Raw Material on the Nutrients and Antioxidant Activities of Apple Juice
}

\author{
Shaoying Zhang and Rui Zhang \\ College of Food Science, Shanxi Normal University, 1 Gongyuan Street, Linfen 041004, China \\ Correspondence should be addressed to Shaoying Zhang; zsynew@163.com
}

Received 14 July 2014; Revised 18 August 2014; Accepted 19 August 2014; Published 26 August 2014

Academic Editor: Franco P. Pedreschi

Copyright (C) 2014 S. Zhang and R. Zhang. This is an open access article distributed under the Creative Commons Attribution License, which permits unrestricted use, distribution, and reproduction in any medium, provided the original work is properly cited.

\begin{abstract}
Microwave technology has been widely applied in food processing. To investigate the effects of microwave pretreatment of raw material on the nutrients and antioxidant activities of apple juice, the apple materials were treated with 90, 270, 450, 720, and 900 W microwave at $25,50,75,100$, and $125 \mathrm{~s}$, respectively. The results showed that after the raw materials were treated with microwave, the vitamin C, amino nitrogen, and anthocyanin content decreased, and the total flavonoids and polyphenol of apple juice increased. Further, the total polyphenol of apple juice originating from raw material treated with $900 \mathrm{~W}$ microwave through $75 \mathrm{~s}$ was $115 \%$ higher than that of control samples. The antioxidant activities of prepared apple juice increased in terms of diphenyl-picryl hydrazyl, superoxide anion and hydroxyl radical scavenging capacity, reducing power, and iron chelating activity. So appropriate microwave pretreatment of apple raw material could increase some specific nutrients and enhance the antioxidant activities of apple juice.
\end{abstract}

\section{Introduction}

Apple juice is one of popular fruit juices owing to its delicious flavor and abundant nutrients such as vitamin C, polyphenol, and flavonoid [1]. In recent years, apple juice trade showed growing trend in the world. The apple juice production of China in 2012 reached 660,000 tons, approximately accounting for about $60 \%$ of the world production [2]. However, apple juice quality is adversely affected by browning and nutrients loss during processing and storage. To maintain its quality, some measures including heating juice, resin adsorption, and adding phytic acid to juice in the processing were put into practice $[3,4]$.

Microwaves are a form of electromagnetic radiation with wavelengths from one millimeter to one meter. There are two effects when food is treated with microwave. One is heating effect that induces the friction of polar molecule of food inner and generates a considerable amount of heat. The other is irradiation effect. These two effects can all cause the changes of food processing characters [5]. Microwave technology has been widely applied in food processing, especially in juice processing. Gerard and Roberts [6] found that heating apple mash with microwave could improve juice yield and quality. Cañumir et al. [7] treated apple juice with microwave to reduce Escherichia coli. Apple juice pasteurisation at 720$900 \mathrm{~W}$ for $60-90 \mathrm{~s}$ resulted in a $2-4$ logs population reduction. In our previous study, we found that pretreatment of raw apple with the microwave power of 720-900 W and time of $75-125$ s could effectively relieve the browning of apple juice [8].

At present, there are few reports regarding the effects of microwave pretreatment of raw material on nutrients and antioxidant activities of juice. The objective of this work was to investigate the variations of nutrients and antioxidant activities of apple juice through microwave pretreatment of raw material at different power and time. The current study may provide reference for fruit juice processing and enrich the related microwave technology in the food industry.

\section{Material and Methods}

2.1. Materials. Apples (Malus pumila Mill. cv. Red Fuji) at the physiologically mature stage with no insect pest and mechanical damages were purchased from an orchard in the outskirts 
of Linfen city. After harvest, they were quickly transported in open cartons to the laboratory of fruit and vegetable processing and were prepared to be apple juice in 24 hours.

Methanol, alcohol, 2,6-dichlorophenolindophenol, oxalic acid, sodium hydroxide, rutin, gallic acid, sodium nitrite, aluminum muriate, sodium carbonate, potassium chloride, sodium acetate, diphenyl-picryl hydrazyl, potassium ferricyanide, ferric chloride, ferrozine, pyrogallol, and salicylic acid (analytical grade) were purchased from Kermel Chemical Reagent Co., Ltd., (Tianjin, China). Pectinase and amylase (biochemical reagent) were purchased from Ruji Biotechnical Co., Ltd., (Shanghai, China). Alfa Aesar Company (Tianjin, China) supplied other reagents.

2.2. Preparation of Apple Juice. Apples were cleaned and cut into small cubes with the length of approximately $1 \mathrm{~cm}$. For each treatment, $200 \mathrm{~g}$ of apple samples with peel was treated at different power for different durations using a microwave oven (WD900Y1SL23-2, Shunde Galanz Electric Appliance Co., Ltd., China). The samples were smashed with a triturator (DS-1, Shanghai Jingke Instrument Company, China) and then filtered with a 200-mesh sieve to obtain a cloudy apple juice. The juice was filled with $500 \mathrm{~mL}$ beaker, heated at $98^{\circ} \mathrm{C}$ for $60 \mathrm{~s}$, and then promptly cooled to $51^{\circ} \mathrm{C}$. $0.1 \mathrm{~g}$ of amylase and $0.1 \mathrm{~g}$ of pectinase were added into the juice. The juice was left stationary for approximately $2 \mathrm{~h}$ at $50 \sim 53^{\circ} \mathrm{C}$ until starch and pectin were decomposed. Subsequently, the juice was filtered with a $0.22 \mu \mathrm{m}$ membrane [9]. All apple juices were diluted to 10.0 Brix with deionised water. The $\mathrm{pH}$ value of prepared apple juice was about 4.0 and the titratable acidity of apple juice was about $260 \mathrm{mg} \cdot 100 \mathrm{~mL}^{-1}$.

2.3. Experimental Design. The raw material was treated with microwave at 90, 270, 450, 720, and $900 \mathrm{~W}$ for $25,50,75,100$, and $125 \mathrm{~s}$. The untreated sample served as the control. Each treatment had three repetitions. The longest treating time was $125 \mathrm{~s}$ to prevent excessive water loss. Water was supplemented when the apple samples were smashed. Water loss in the experiment was below $2.5 \%$.

\subsection{Determination of Related Indexes}

2.4.1. Qualitative Determination of Pectin and Starch. Pectin and starch were qualitatively detected as follows [10]. Briefly, acidulated alcohol was prepared through adding $1 \mathrm{~mL}$ of $37 \%$ hydrochloric acid into $99 \mathrm{~mL}$ of anhydrous ethyl alcohol. $100 \mathrm{~mL}$ of apple juice undergoing pectinase enzymolysis was filtered with a $0.22 \mu \mathrm{m}$ membrane. Acidulated alcohol $(20 \mathrm{~mL})$ was added into $10 \mathrm{~mL}$ of filtered juice. The mixture was slightly inverted three times and was left stationary for 15 30 min. The formation of gelatin or floccule suggested the presence of pectin in the apple juice, whereas the absence of gelatin or floccule indicated the decomposition of pectin.

Starch was qualitatively detected according to the following methods. Iodine $(0.065 \mathrm{~g})$ and potassium iodide $(1.75 \mathrm{~g})$ were dissolved with a small amount of deionised water. The solution was diluted to $500 \mathrm{~mL}$ and placed in a brown volumetric flask to yield a $0.005 \mathrm{~mol} \cdot \mathrm{L}^{-1}$ iodine solution. Apple juice $(20 \mathrm{~mL})$ through amylase enzymolysis was filtered with a $0.22 \mu \mathrm{m}$ membrane. Subsequently, $1 \mathrm{~mL}$ of $0.005 \mathrm{~mol} \cdot \mathrm{L}^{-1}$ iodine solution was added into the juice. A colour reaction between the juice and iodine was observed. Yellow indicated the absence of starch, brown suggested the presence of a small amount of starch, and blue indicated the presence of a large amount of starch in the apple juice.

\subsubsection{Determination of Vitamin $C$ and Ammonia Nitrogen} Content. The vitamin $\mathrm{C}$ content was measured by 2,6-dichloroindophenol titration [11]. Briefly, $2 \mathrm{~mL}$ of apple juice was titrated to a permanent pink colour using $0.1 \%$ of 2,6 -dichlorophenolindophenol solution dissolved with $1 \%$ oxalic acid. The vitamin $\mathrm{C}$ concentration was calculated according to the titration volume of 2,6-dichloroindophenol and expressed as mg $100 \mathrm{~mL}^{-1}$ apple juice.

Ammonia nitrogen content was determined according to the method of Grissom [12] with slight modification. Apple juice $(5 \mathrm{~g})$ was diluted with $100 \mathrm{~mL}$ of deionised water and then titrated with $0.05 \mathrm{~mol} \cdot \mathrm{L}^{-1}$ sodium hydroxide until the $\mathrm{pH}$ value of the juice solution reached 8.2 within $1 \mathrm{~min}$. Subsequently, $10 \mathrm{~mL}$ of neutral formaldehyde was added into the juice solution. The juice solution was titrated until the $\mathrm{pH}$ value reached 9.2. The volume of consumed sodium hydroxide was recorded, and the content of ammonia nitrogen was calculated per $100 \mathrm{~g}$ apple juice.

2.4.3. Determination of Total Flavonoids, Polyphenol, and Anthocyanins. Total flavonoid content was measured according to a colorimetric assay [13]. A 1-mL aliquot of standard solution of rutin at different concentrations $(0,10,20,30$, 40 , and $50 \mathrm{mg} \mathrm{L}^{-1}$ ) or appropriately diluted apple juice was added to $10-\mathrm{mL}$ volumetric flasks containing $4 \mathrm{~mL}$ water. At the onset of the experiment, $0.4 \mathrm{~mL}$ of $5 \% \mathrm{NaNO}_{2}$ was added to the flask. After $6 \mathrm{~min}, 0.4 \mathrm{~mL}$ of $10 \% \mathrm{AlCl}_{3}$ was added. At $6 \mathrm{~min}, 4 \mathrm{~mL}$ of $4 \% \mathrm{NaOH}$ was added to the mixture. Immediately, the solution was diluted to a final volume of $10 \mathrm{~mL}$ with water and mixed thoroughly. The absorbance of the mixture was determined at $510 \mathrm{~nm}$ versus the prepared blanks. Total flavonoid content was expressed as mg rutin equivalents per $100 \mathrm{~mL}$ apple juice.

Total polyphenol content was determined using FolinCiocalteu's phenol reagent via spectrophotometric analysis [14]. An aliquot $(1 \mathrm{~mL})$ of a standard solution of gallic acid of concentrations including $0,10,20,30,40$, and $50 \mathrm{mg} \mathrm{L}^{-1}$ aqueous methanol, or appropriately diluted apple juice was added to a $25 \mathrm{~mL}$ volumetric flask containing $9 \mathrm{~mL}$ of water. About $1 \mathrm{~mL}$ of Folin-Ciocalteu's phenol reagent was added to the mixture and shaken. After $8 \mathrm{~min}, 2 \mathrm{~mL}$ of $7.5 \%$ aqueous $\mathrm{Na}_{2} \mathrm{CO}_{3}$ solution was added. The solution was then immediately diluted to a final volume of $25 \mathrm{~mL}$ with water and thoroughly mixed. After incubation for $30 \mathrm{~min}$ at $25^{\circ} \mathrm{C}$, the absorbance versus the prepared blanks was read at $765 \mathrm{~nm}$. Total polyphenol content was expressed as $\mu \mathrm{g}$ gallic acid equivalents per $100 \mathrm{~mL}$ apple juice.

The quantification of total anthocyanins was evaluated by the $\mathrm{pH}$ differential method [15]. An aliquot $(1 \mathrm{~mL})$ of appropriately diluted apple juice in both $0.025 \mathrm{M}$ potassium chloride solution $(\mathrm{pH} 1.0 ; 1.86 \mathrm{~g} \mathrm{KCl}$ in $1 \mathrm{~L}$ water adjusted to 
$\mathrm{pH}$ with concentrated $\mathrm{HCl}$ ) and $0.4 \mathrm{M}$ sodium acetate buffer (54.43 $\mathrm{g} \mathrm{CH}_{3} \mathrm{CO}_{2} \mathrm{Na} \cdot 3 \mathrm{H}_{2} \mathrm{O}$ in $1 \mathrm{~L}$ water adjusted to $\mathrm{pH} 4.5$ with concentrated $\mathrm{HCl}$ ) was measured at both 510 and $700 \mathrm{~nm}$ after $15 \mathrm{~min}$ of incubation at $23^{\circ} \mathrm{C}$. The content of total anthocyanins was expressed as $\mu \mathrm{g}$ g cyanidin 3-glucoside equivalents per $100 \mathrm{~mL}$ apple juice. A molar absorption coefficient of $26,900 \mathrm{~L} \mathrm{~mol}^{-1} \mathrm{~cm}^{-1}$ was used to calculate the concentration of cyanidin 3-glucoside in apple juice.

2.4.4. Determination of DPPH Free Radical Scavenging Activity and Reducing Power. DPPH radical scavenging capacity was assayed as described by Yang et al. with slight modifications [16]. Briefly, $3 \mathrm{~mL}$ of appropriately diluted apple juice was added to $3 \mathrm{~mL}$ of DPPH $\left(120 \mu \mathrm{mol} \cdot \mathrm{L}^{-1}\right)$ in methanol. After the reaction mixtures were incubated for $1 \mathrm{~h}$ at $30^{\circ} \mathrm{C}$ in the dark, its absorbance at $517 \mathrm{~nm}$ was determined using a spectrophotometer (UV-1100, Shanghai Meipuda Instrument Co., Ltd., Shanghai, China). The scavenging rate of DPPH radicals was calculated as scavenging rate $(\%)=\left[1-\left(A_{1}-\right.\right.$ $\left.\left.A_{s}\right) / A_{0}\right] \times 100$, where $A_{0}$ is the absorbance of the control solution ( $3 \mathrm{~mL}$ of phosphate-buffered saline in $3 \mathrm{~mL}$ of DPPH solution), $A_{1}$ is the absorbance of the apple juice in DPPH solution, and $A_{s}$, which is used for error correction arising from unequal colour of the sample solutions, is the absorbance of the apple juice without DPPH.

The reducing power of the fruit samples was determined using the method of Jayaprakasha et al. [17]. A $0.5 \mathrm{~mL}$ aliquot of appropriately diluted apple juice was mixed with $2.5 \mathrm{~mL}$ of phosphate buffer $(0.2 \mathrm{M}, \mathrm{pH} 6.6)$ and $2.5 \mathrm{~mL}$ of $1 \%$ potassium ferricyanide in $10 \mathrm{~mL}$ test tubes. The mixtures were incubated for $20 \mathrm{~min}$ at $50^{\circ} \mathrm{C}$. After incubation, $1 \mathrm{~mL}$ of $10 \%$ trichloroacetic acid was added to the mixtures, followed by centrifugation at $5000 \times \mathrm{g}$ for $10 \mathrm{~min}$ with an Eppendorf $5417 \mathrm{R}$ centrifuge (Germany). The upper layer $(2.5 \mathrm{~mL})$ was mixed with $2.5 \mathrm{~mL}$ of distilled water and $1 \mathrm{~mL}$ of $0.1 \%$ ferric chloride. The absorbance was measured at $700 \mathrm{~nm}$. The increase in absorbance of the reaction mixture indicated the reducing power of the samples.

2.4.5. Determination of $\mathrm{Fe}^{2+}$ Chelating Activity. The $\mathrm{Fe}^{2+}$ chelating activity was determined by measuring the formation of the $\mathrm{Fe}^{2+}$-ferrozine complex [18]. $0.5 \mathrm{~mL}$ of apple juice was mixed with $2 \mathrm{~mL}$ of $0.1 \mathrm{M}$ sodium acetate buffer $\mathrm{pH} 4.9$ and $0.05 \mathrm{~mL}$ of $\mathrm{FeCl}_{2}(2 \mathrm{mM})$. After $30 \mathrm{~min}$ of incubation at room temperature, $0.2 \mathrm{~mL}$ of $5 \mathrm{mM}$ ferrozine was added. After $10 \mathrm{~min}$ at room temperature, the absorbance of the $\mathrm{Fe}^{2+}$ ferrozine complex was measured at $562 \mathrm{~nm}$. The chelating activity of the apple juice for $\mathrm{Fe}^{2+}$ was calculated as chelating rate $(\%)=\left[\left(A_{0}-A_{1}\right) / A_{0}\right] \times 100$, where $A_{0}$ was the absorbance of the control (blank, without apple juice) and $A_{1}$ was the absorbance in the presence of the apple juice.

2.4.6. Determination of Scavenging Activities of Superoxide Anion and Hydroxyl Radical. For superoxide anion radical assay, the superoxide anion radicals were generated by a pyrogallol autoxidation system [19]. $4.5 \mathrm{~mL}$ of Tris- $\mathrm{HCl}$ buffer solution $\left(50 \mathrm{mmol} \cdot \mathrm{L}^{-1}, \mathrm{pH} 8.2\right)$ and $0.5 \mathrm{~mL}$ of deionized water were added into a test tube, and the test tube was incubated in a water bath at $25^{\circ} \mathrm{C}$ for $20 \mathrm{~min}$. A volume of $0.4 \mathrm{~mL}$ of pyrogallol solution $\left(25 \mathrm{mmol} \cdot \mathrm{L}^{-1}\right.$ of pyrogallol in $10 \mathrm{mmol} \cdot \mathrm{L}^{-1}$ of $\mathrm{HCl}$ ), which was also preincubated at $25^{\circ} \mathrm{C}$, was injected to the above test tube with a microliter syringe and mixed. The mixture was incubated at $25^{\circ} \mathrm{C}$ for $3 \mathrm{~min}$ and then $1 \mathrm{~mL}$ of $10 \mathrm{~mol} \cdot \mathrm{L}^{-1} \mathrm{HCl}$ was dripped into the mixture promptly to terminate the reaction. The absorbance at $420 \mathrm{~nm}$ marked as $A_{0}$ was measured 5 min later, and this $A_{0}$ denotes the speed of pyrogallol autoxidation. The $A_{1}$ autoxidation speed was obtained applying the above method and with the addition of $0.5 \mathrm{~mL}$ apple juice substituting for deionized water into the Tris- $\mathrm{HCl}$ buffer solution. Simultaneously, a blank control of apple juice was obtained as $A_{2}$. The scavenging percentage was calculated according to the following formula: superoxide radical scavenging effect $(\%)=$ $\left[A_{0}-\left(A_{1}-A_{2}\right)\right] / A_{0} \times 100$.

The hydroxyl radicals were generated in an $\mathrm{H}_{2} \mathrm{O}_{2}-\mathrm{FeSO}_{4}$ system by oxidation of $\mathrm{FeSO}_{4}$ and were assayed by the color change of salicylic acid [20]. The hydroxyl radicals were generated in $7.0 \mathrm{~mL}$ of reactive solution containing $2.0 \mathrm{~mL}$ of $6 \mathrm{mmol} \cdot \mathrm{L}^{-1} \mathrm{FeSO}_{4}, 2.0 \mathrm{~mL}$ of $6 \mathrm{mmol} \cdot \mathrm{L}^{-1}$ salicylic acid, $2.0 \mathrm{~mL}$ of $6 \mathrm{mmol} \cdot \mathrm{L}^{-1} \mathrm{H}_{2} \mathrm{O}_{2}$, and $1.0 \mathrm{~mL}$ of apple juice. The mixture was incubated at $37^{\circ} \mathrm{C}$ for $1 \mathrm{~h}$. The change in absorbance caused by the color change of salicylic acid was measured at $510 \mathrm{~nm}$. The inhibition of hydroxyl radicals production was calculated as follows: inhibition rate $(\%)=\left[A_{0}-\right.$ $\left.\left(A_{1}-A_{2}\right)\right] / A_{0} \times 100$, where $A_{0}$ was the absorbance of the above group replacing apple juice with deionized water, $A_{1}$ was the absorbance of the apple juice group, and $A_{2}$ was the absorbance of a blank control of apple juice.

2.5. Statistical Analysis. The data were processed by analysis of variance using DPS7.05 statistical software (Refine Information Tech. Co., Ltd., Hangzhou, China). The treatments were compared at $P=0.05$ using Tukey's test, which indicates the multicomparison value in each case. The data were expressed as mean \pm standard deviation (SD).

\section{Results and Analysis}

3.1. Vitamin $C$ and Ammonia Nitrogen Content. As shown in Figure 1(a), the vitamin $\mathrm{C}$ content of apple juice decreased with microwave power enhancement or treating time extension. It decreased the least in $90 \mathrm{~W}$ and the most in $900 \mathrm{~W}$. When raw apple material was treated with microwave for $25 \mathrm{~s}$, the vitamin $C$ content of apple juice declined less. With the treating time duration up to $125 \mathrm{~s}$, much more vitamin $\mathrm{C}$ of apple juice is lost. The vitamin $\mathrm{C}$ content of apple juice treated with $900 \mathrm{~W} 125 \mathrm{~s}$ microwave is $1.34 \mathrm{mg} \cdot 100 \mathrm{~mL}^{-1}$, which is $28.4 \%$ compared to that of untreated samples. As described in Figure 1(b), similar to vitamin $\mathrm{C}$, the ammonia nitrogen content of apple juice also demonstrated down trend with the microwave power increase or time duration.

3.2. Total Flavonoids, Phenolics, and Anthocyanins Content of Apple Juice. After microwave pretreatment of raw material, the total flavonoid contents of all apple juice enhanced (Figure 2(a)). From $90 \mathrm{~W}$ to $450 \mathrm{~W}$, they increased 


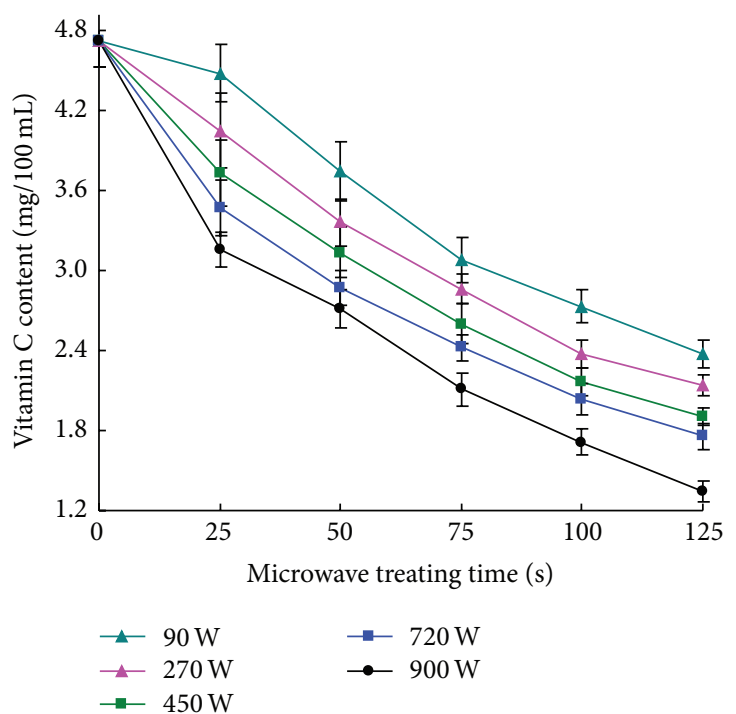

(a)

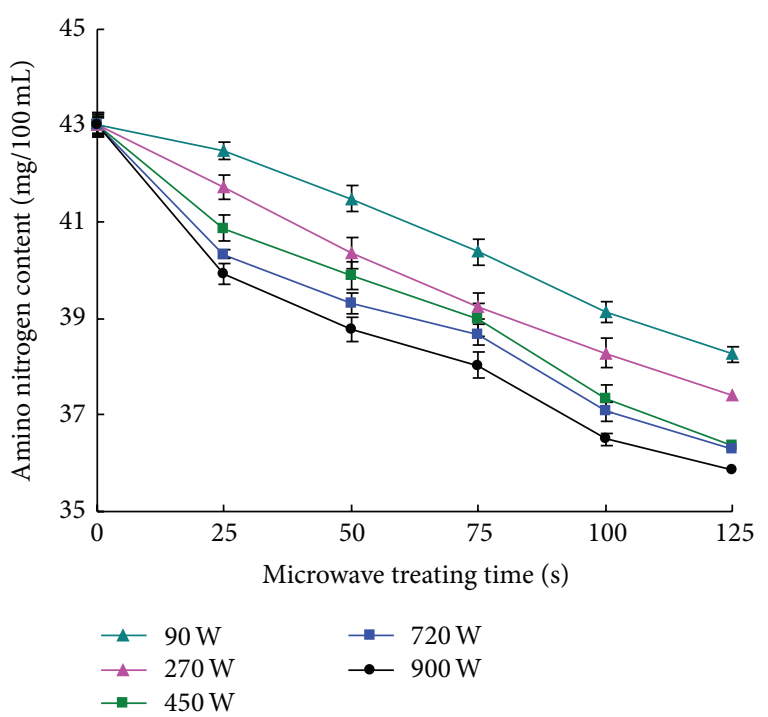

(b)

Figure 1: Effect of microwave pretreatment of raw apple material on the vitamin $\mathrm{C}$ and ammonia nitrogen content of apple juice. Each point represents the mean value \pm SD.

with microwave power enlargement and time extension. Through pretreatment of raw material with $720 \mathrm{~W}$ or $900 \mathrm{~W}$ microwave, the total flavonoid contents of apple juice increased with time duration between $0 \mathrm{~s}$ and $100 \mathrm{~s}$. And they reached to the maximum at $100 \mathrm{~s}$. Afterward, the total flavonoid showed down trend. Further, between $75 \mathrm{~s}$ and $100 \mathrm{~s}$, the total flavonoid content of apple juice, prepared with raw material treated with higher microwave power such as $720 \mathrm{~W}$ or $900 \mathrm{~W}$, was significantly higher than that of apple juice prepared with low power treatment of raw material $(P<$ $0.05)$.

As described in Figure 2(b), after pretreatment of raw material with microwave, total polyphenol content of apple juice showed increasing trend. Moreover, the apple juice prepared with higher microwave pretreatment of raw material contained much more polyphenol. Though total polyphenol of apple juice of raw material treated with $90 \mathrm{~W}$ and $270 \mathrm{~W}$ microwave increased from $0 \mathrm{~s}$ to $125 \mathrm{~s}$, it enhanced slower, whereas the total polyphenol of apple juice of raw material treated with $450 \mathrm{~W}, 720 \mathrm{~W}$, or $900 \mathrm{~W}$ firstly increased and then decreased with microwave treating time extension. The apple juice of raw material treated with $900 \mathrm{~W}$ $75 \mathrm{~s}$ demonstrated the maximum total polyphenol content $\left(328.1 \mu \mathrm{g} \cdot 100 \mathrm{~mL}^{-1}\right)$, which was $115 \%$ higher than that of control samples while the total polyphenol contents of apple juice of raw material treated with $450 \mathrm{~W}$ or $720 \mathrm{~W}$ microwave also reached to the maximum at $100 \mathrm{~s}$ microwave, and they were $111 \%$ or $104 \%$ higher than control samples, respectively.

The total anthocyanins content of apple juice of raw material treated with microwave decreased with microwave power enhancement and time duration (Figure 2(c)). It decreased much slower when the raw material was treated with $90 \mathrm{~W}$ microwave and decreased to $480.4 \mu \mathrm{g} \cdot 100 \mathrm{~mL}^{-1}$ at $125 \mathrm{~s}$, which is $34.4 \%$ lower than that of control samples.
However, the total anthocyanins content of apple juice promptly decreased when the material was treated with $900 \mathrm{~W}$ microwave. It was very low at $75 \mathrm{~s}$. And from $75 \mathrm{~s}$ to $125 \mathrm{~s}$, there were no significant differences among the total anthocyanins contents of apple juice of raw material treated with $900 \mathrm{~W}$ microwave $(P>0.05)$.

3.3. DPPH Free Radical Scavenging Activity and Reducing Power. As shown in Figure 3(a), DPPH radical scavenging capacity of apple juice increased after the raw materials were treated with microwave compared to that of control samples. Apple juice prepared with $720 \mathrm{~W}$ and $900 \mathrm{~W}$ treating materials showed stronger DPPH radical scavenging ability, and the highest value of scavenging DPPH radical appeared at $75 \mathrm{~s}$ and $100 \mathrm{~s}$, but there was slight decline at $125 \mathrm{~s}$. The apple juice prepared with raw material treated with $90 \mathrm{~W}$ microwave showed the lowest DPPH radical scavenging capacity, whereas apple juice prepared with raw material through $270 \mathrm{~W}$ and $450 \mathrm{~W}$ microwave treatment showed medium level to scavenge DPPH radical. As described from Figure 3(b), the apple juice treated with $720 \mathrm{~W}$ microwave demonstrated the strongest reducing ability, but the apple juice treated with $90 \mathrm{~W}$ microwave showed the lowest reducing ability. And the reducing powers of apple juice originating from raw material treated with $450 \mathrm{~W}$ and $900 \mathrm{~W}$ were almost the same.

3.4. $\mathrm{Fe}^{2+}$ Chelating Activity. Iron chelating activity of apple juice of treated raw material with microwave showed increase trend, emerging complex variation (Figure 4). Apple juice originating from raw material treated with 720 and $900 \mathrm{~W}$ microwave demonstrated higher chelating activity than that of raw material treated with 90, 270, and $450 \mathrm{~W}$. There were two peak values of iron chelating activity, appearing at $25 \mathrm{~s}$ 


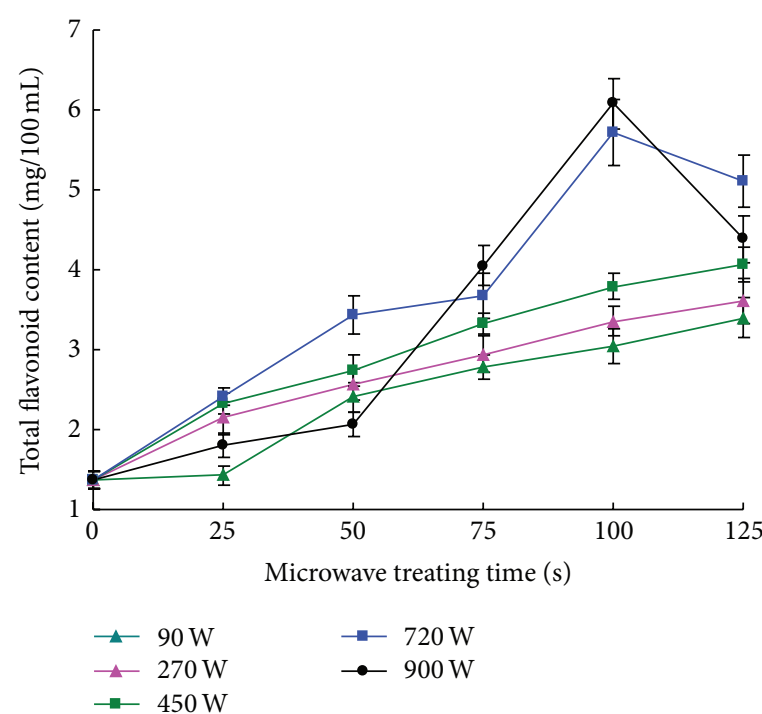

(a)

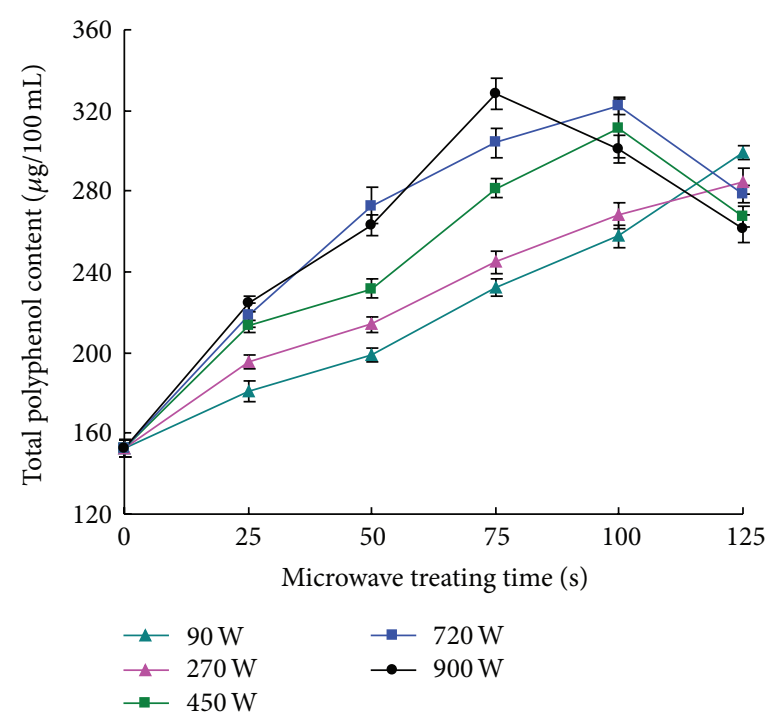

(b)

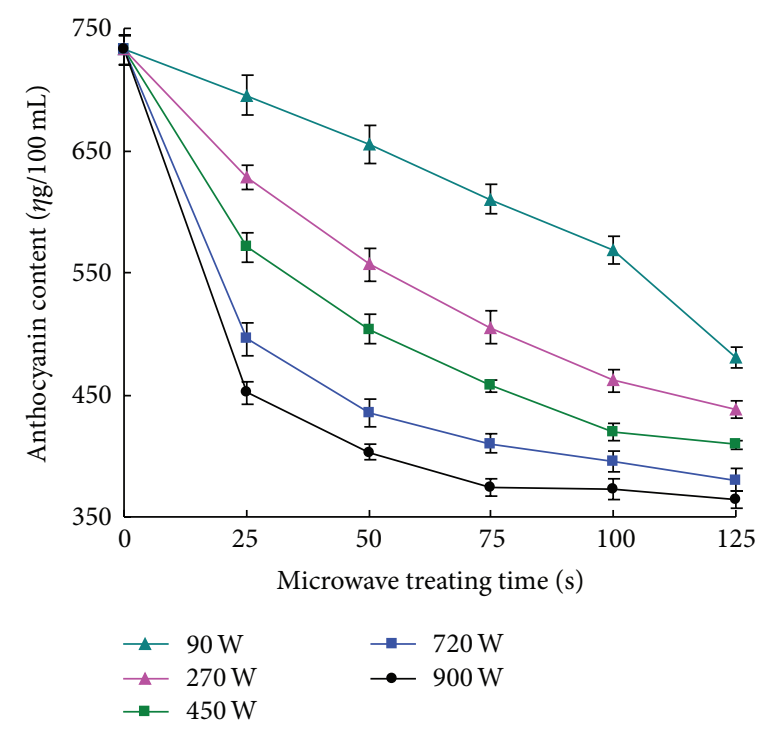

(c)

FiguRE 2: Effect of microwave pretreatment of raw apple material on total flavonoids, phenolics, and anthocyanins content of apple juice. Each point represents the mean value \pm SD.

and $100 \mathrm{~s}$, respectively, and the value at $100 \mathrm{~s}$ was much higher than that of $25 \mathrm{~s}$, whereas, through treating of raw material with $90 \mathrm{~W}$ and $270 \mathrm{~W}$ microwave, iron chelating activity of prepared apple juice increased with time extension. The apple juice prepared with $450 \mathrm{~W} 25 \mathrm{~s}$ treated raw material also displayed a peak value at $25 \mathrm{~s}$ and then showed increasing trend from $50 \mathrm{~s}$ to $125 \mathrm{~s}$.

3.5. The Scavenging Activities of Superoxide Anion and Hydroxyl Radical. As shown in Figure 5(a), the superoxide anion scavenging of all apple juice prepared with treated raw material using microwave increased with varying degrees.
The apple juice of treated raw material with $720 \mathrm{w}$ and $900 \mathrm{w}$ microwave demonstrated very strong capacity to scavenge superoxide anion between $75 \mathrm{~s}$ and $100 \mathrm{~s}$, but it decreased at $125 \mathrm{~s}$, while the superoxide anion scavenging capacity of apple juice originating from $90 \mathrm{~W}$ treated raw material was low generally. Figure 5(b) indicated that the trend of hydroxyl radical scavenging activity of apple juice of treated raw material with microwave was similar to that of superoxide anion scavenging capacity. After the raw material was treated with $720 \mathrm{~W}$ or $900 \mathrm{~W}$, the prepared apple juice showed stronger hydroxyl radical scavenging activity. And apple juice of the $450 \mathrm{~W}$ treated raw material demonstrated the medium hydroxyl radical scavenging activity. There was weaker reveal 


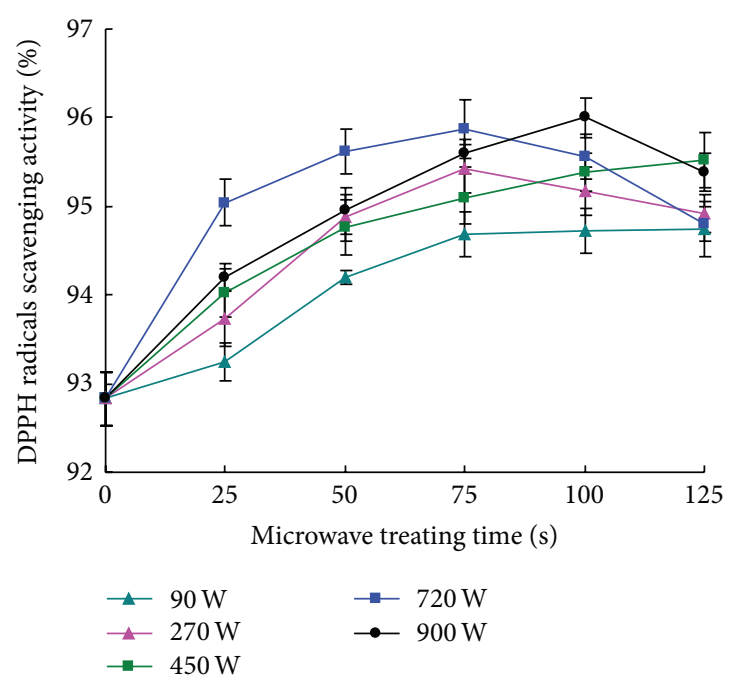

(a)

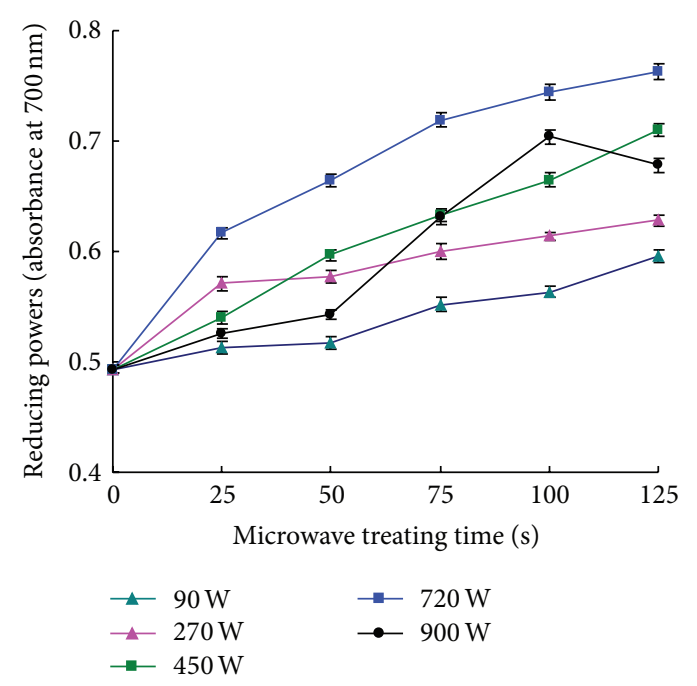

(b)

FIGURE 3: Effect of microwave pretreatment of raw apple material on DPPH free radical scavenging activity and reducing power of apple juice. Each point represents the mean value $\pm \mathrm{SD}$.

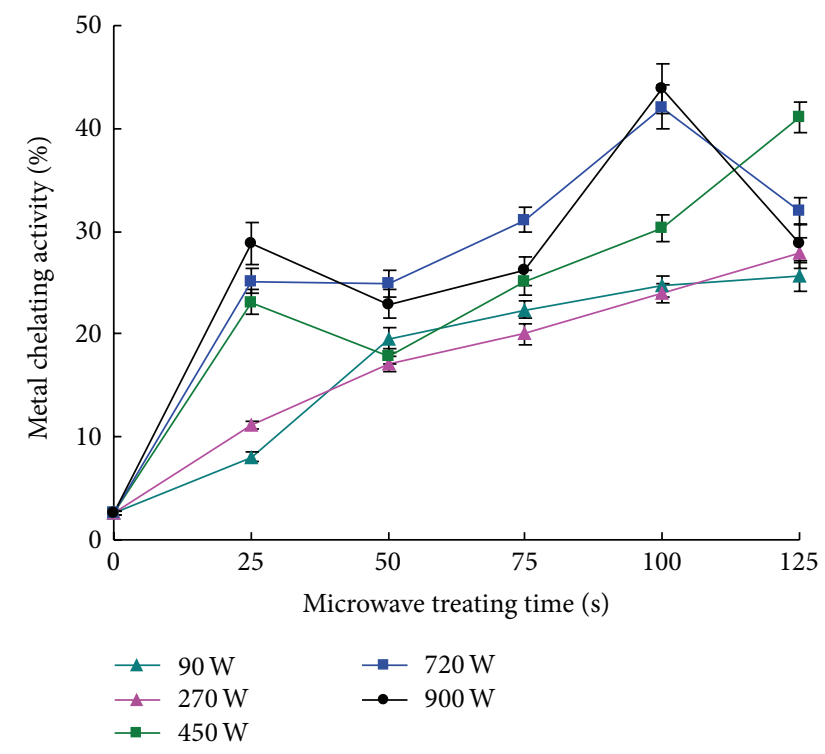

FIGURE 4: Effect of microwave pretreatment of raw apple material on $\mathrm{Fe}^{2+}$ chelating activity of apple juice. Each point represents the mean value \pm SD.

in apple juice originating from $90 \mathrm{~W}$ and $270 \mathrm{~W}$ treated raw material as well.

\section{Discussion}

Microwave has thermal effect; namely, it causes the friction of polar molecules in material internal and much heat is generated [20]. After raw material was treated with microwave, the vitamin $\mathrm{C}$, amino nitrogen, and anthocyanin content decreased with microwave power enhancement or time extension compared to control sample $(P<0.05)$. Vitamin $C$ and anthocyanins are all thermal sensitive polar molecules. They were prone to degradation once the raw material was treated with microwave. Though amino acid is relatively stable in fruit tissue, it was likely to react with some reducing sugar and lead to Maillard reaction under the microwave irradiation. Therefore, the amino nitrogen content of apple juice decreased [21].

Flavonoids and polyphenols of apple juice are important functional nutrients, showing an increasing trend after the raw material was treated with microwave compared to control samples $(P<0.05)$. The reason may be that after microwave properly treated raw material, some enzymes in fruit tissue were activated. The activated enzymes more effectively prompt other substances into flavonoids and polyphenols [22]. Additionally, microwave treatment probably released some flavonoid or polyphenol compounds that were jointed to proteins or amino acids. After the raw material was treated with microwave power such as $720 \mathrm{~W}$ and $900 \mathrm{~W}$, the apple juice contained more flavonoids. This may verify the importance of thermal effect. Moreover, Kim et al. [23] also found that thermal processing affected quantities of each phenolic acid and flavonoid component. The total phenolic content and total flavonoid content of the garlic subjected to different thermal processing steps were higher than those of fresh garlic [23]. However, excessive thermal effect could lead to the degradation of flavonoids and polyphenols [24]. For example, the flavonoids and polyphenols content of apple juice originating from raw material treated with $900 \mathrm{~W} 125 \mathrm{~s}$ microwave decreased compared to those of $100 \mathrm{~s}$ (Figure 2).

After microwave pretreatment of raw apple material, the antioxidant activities of apple juice all increased with varying degree compared to control samples $(P<0.05)$. DPPH radical scavenging capacity indicates the ability of supplying hydrogen atom of apple juice [25]. After the raw material was 


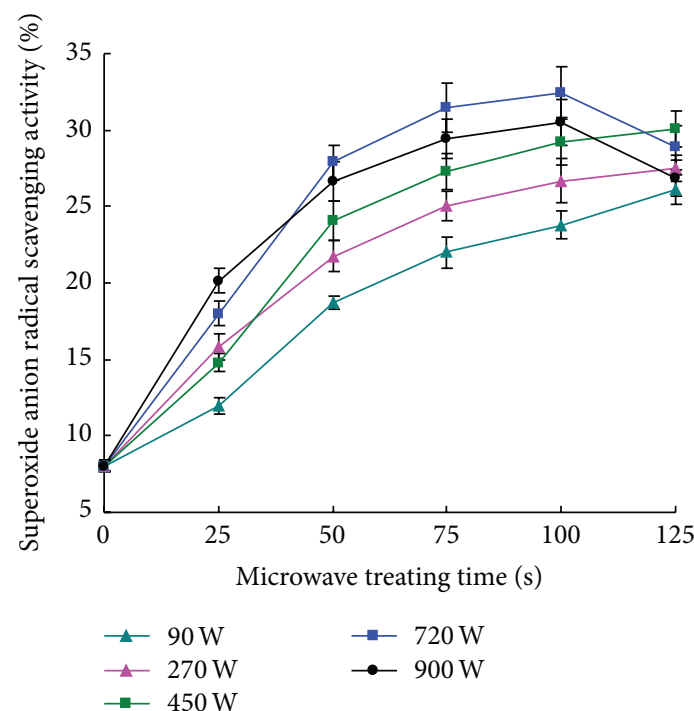

(a)

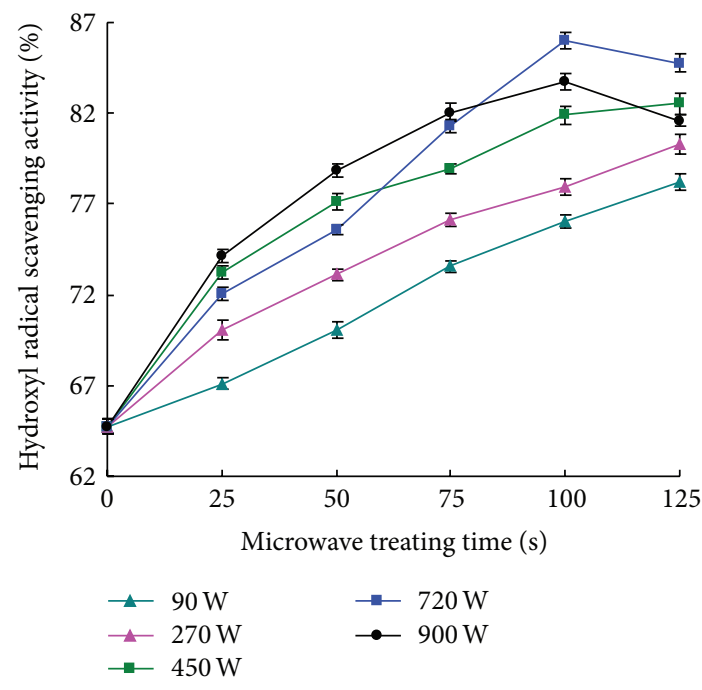

(b)

FIGURE 5: Effect of microwave pretreatment of raw apple material on the scavenging activities of superoxide anion and hydroxyl radical of apple juice. Each point represents the mean value \pm SD.

treated with $720 \mathrm{~W}$ and $900 \mathrm{~W}$ microwave between $75 \mathrm{~s}$ and $100 \mathrm{~s}$, the prepared apple juice had stronger ability to scavenge DPPH radical (Figure 3(a)). This suggested that microwave pretreatment might enhance the substance of hydrogen donor. The above result was consistent with increased flavonoids and polyphenols (Figure 2). Reducing power exhibited the capability of providing electronic of substance [26].720 W microwave mostly contributed to the formation of providing electronic substance in apple juice (Figure 3(b)). Chelating ability enhancement may be attributed to increased flavonoids content and Mallard reaction. The reduction of amino nitrogen indirectly proved that Maillard reaction reacted after microwave pretreated raw material (Figure 1(b)) [27]. Superoxide anion and hydroxyl radical as free radical lie in organism tissue and their accumulation could damage cell and lead to much syndromes [28]. After the raw material was treated with $720 \mathrm{~W}$ or $900 \mathrm{~W}$ microwave through $75 \sim 100 \mathrm{~s}$, the prepared apple juice could effectively scavenge superoxide anion and hydroxyl radical. The result suggested that though appropriate microwave pretreatment of raw apple material might significantly enhance the biological activity of apple juice, microwave pretreatment of raw material reduced the vitamin $\mathrm{C}$ and anthocyanins content of apple juice but significantly increased the flavonoids and polyphenols content.

As for the orders of magnitude, after the raw material was treated with $720 \mathrm{~W}$ or $900 \mathrm{~W}$ microwave between $75 \mathrm{~s}$ and $100 \mathrm{~s}$, the flavonoids content in apple juice was about 10 times of that of anthocyanin and 20 times of that of polyphenols. Therefore, microwave treatment was beneficial to preserve the specific nutrients such as flavonoids to some degree. More flavonoids were advantageous to enhance the antioxidant activity of apple juice. Considering the development and application of microwave, treating of raw material with $720 \mathrm{~W}$ and $900 \mathrm{~W}$ between $75 \mathrm{~s}$ and $125 \mathrm{~s}$ could effectively control the enzymatic browning of apple juice. This is of great importance to ensure the apple juice quality [8]. Besides that, microwave treatment could improve apple juice yield that is quite necessary to the economic benefit of the manufacturer [6]. Yet as for microwave application in apple juice processing, the enhancement of microwave power or extension of time was limited. Excessive treatment of raw material with microwave could cause the large loss of water in raw apple and damage processing characters in relation to apple juice.

The effect of microwave treatment of raw apple material showed certain dosage effect. When the raw material was treated with small microwave power or short time, microwave effect could not effectively function. At the moment, the flavonoids enhancement of apple juice was little and the antioxidant activity was low. When the raw material was treated with larger power $720 \mathrm{~W}$ or $900 \mathrm{~W}$ during $75 \sim 100 \mathrm{~s}$, the prepared apple juice demonstrated strong antioxidant activity. However, when the treating time lasted for $125 \mathrm{~s}$, the apple juice originating from raw material treated with higher power contained fewer nutrients and displayed weaker antioxidant activity than that of $100 \mathrm{~s}$ treating of raw material. Nevertheless, the antioxidant activity of apple juice prepared with low power treatment of raw material gradually increased from $0 \mathrm{~s}$ to $125 \mathrm{~s}$. The antioxidant activities of apple juice at $125 \mathrm{~s}$ were complicated. It is an increasing process in lower power microwave and decreasing process in higher power microwave, though in fact the antioxidant activity of apple juice originating from lower power treatment of raw material is not higher than that of higher microwave power raw material.

\section{Conclusion}

After the raw apple material was treated with microwave, the vitamin $\mathrm{C}$, amino nitrogen, and anthocyanin content 
decreased with microwave enhancement and time extension, and the total flavonoids and polyphenol contents of apple juice increased with microwave enlargement or time duration. Further, the apple juice originating from raw material treated with $720 \mathrm{~W}$ or $900 \mathrm{~W}$ microwave through $100 \mathrm{~s}$ contained more flavonoids and polyphenols. Microwave pretreatment of raw apple material could improve the antioxidant activities of prepared apple juice. The DPPH radical scavenging capacity of apple juice firstly increased and then decreased generally with the microwave power enhancement or time extension. In addition, through pretreatment of raw material with $720 \mathrm{~W}$ or $900 \mathrm{~W}$ microwave from $75 \mathrm{~s}$ to $100 \mathrm{~s}$, the prepared apple juice demonstrated strong reducing power and iron chelating activity, and it also showed higher capacity to scavenge superoxide anion and hydroxyl radical. Therefore, appropriate microwave pretreatment of raw material could increase some specific nutrients and enhance the antioxidant activities of apple juice.

\section{Conflict of Interests}

The authors declare that there is no conflict of interests regarding the publication of this paper.

\section{Acknowledgments}

This work was supported by Project of the National Natural Science Foundation of China under Grant no. 31101359, by Program for the Innovative Talents of Higher Learning Institutions of Shanxi (2012), and by Project of Natural Science Foundation of Shanxi under Grant no. 2012021025-3.

\section{References}

[1] J. Boyer and R. H. Liu, "Apple phytochemicals and their health benefits," Nutrition Journal, vol. 3, no. 5, article 1, pp. 1-15, 2004.

[2] Y. B. Li, "The yield of apple juice concentrated in China accounted for $60 \%$ of world," Wen Wei Po, 2012, http://paper .wenweipo.com/2012/09/19/FM1209190002.htm.

[3] L. F. Damasceno, F. A. N. Fernandes, M. M. A. Magalhães, and E. S. Brito, "Non-enzymatic browning in clarified cashew apple juice during thermal treatment: kinetics and process control," Food Chemistry, vol. 106, no. 1, pp. 172-179, 2008.

[4] Y. J. Du, S. Q. Dou, and S. J. Wu, "Efficacy of phytic acid as an inhibitor of enzymatic and non-enzymatic browning in apple juice," Food Chemistry, vol. 135, no. 2, pp. 580-582, 2012.

[5] S. Chandrasekaran, S. Ramanathan, and T. Basak, "Microwave food processing-a review," Food Research International, vol. 52, no. 1, pp. 243-261, 2013.

[6] K. A. Gerard and J. S. Roberts, "Microwave heating of apple mash to improve juice yield and quality," LWT_Food Science and Technology, vol. 37, no. 5, pp. 551-557, 2004.

[7] J. A. Cañumir, J. E. Celis, J. de Bruijn, and L. V. Vidal, "Pasteurisation of apple juice by using microwaves," LWT-Food Science and Technology, vol. 35, no. 5, pp. 389-392, 2002.

[8] S. Zhang, X. Wang, Y. Yu, and H. Guo, "Effects of microwave treatment of raw apple on browning of apple juice," Transactions of the Chinese Society of Agricultural Engineering, vol. 26, no. 5, pp. 347-351, 2010 (Chinese).
[9] K. Baert, F. Devlieghere, A. Amiri, and B. De Meulenaer, "Evaluation of strategies for reducing patulin contamination of apple juice using a farm to fork risk assessment model," International Journal of Food Microbiology, vol. 154, no. 3, pp. 119-129, 2012.

[10] C. A. Chopda and D. M. Barrett, "Optimization of guava juice and powder production," Journal of Food Processing and Preservation, vol. 25, no. 6, pp. 411-430, 2001.

[11] O. A. Bessey and C. G. King, "The distribution of vitamin C in plant and animal tissues, and its determination," The Journal of Biological Chemistry, vol. 103, pp. 687-698, 1933.

[12] J. T. Grissom, "The formaldehyde method for determining ammonium nitrate," Industrial and Engineering Chemistry, vol. 12, no. 2, pp. 172-173, 1920.

[13] M. Abid, S. Jabbar, T. Wu et al., "Effect of ultrasound on different quality parameters of apple juice," Ultrasonics Sonochemistry, vol. 20, no. 5, pp. 1182-1187, 2013.

[14] C. Xiao, L. Zhu, W. Luo, X. Song, and Y. Deng, "Combined action of pure oxygen pretreatment and chitosan coating incorporated with rosemary extracts on the quality of fresh-cut pears," Food Chemistry, vol. 121, no. 4, pp. 1003-1009, 2010.

[15] M. Giusti and R. E. Wrolstad, "Characterization and measurement of anthocyanins by UV-visible spectroscopy," in Current Protocols in Food Analytical Chemistry, pp. F1.2.1-F1.2.13, 2001.

[16] Z. F. Yang, Y. H. Zheng, and S. F. Cao, "Effect of high oxygen atmosphere storage on quality, antioxidant enzymes, and DPPH-radical scavenging activity of Chinese bayberry fruit," Journal of Agricultural and Food Chemistry, vol. 57, no. 1, pp. 176-181, 2009.

[17] G. K. Jayaprakasha, R. P. Singh, and K. K. Sakariah, "Antioxidant activity of grape seed (Vitis vinifera) extracts on peroxidation models in vitro," Food Chemistry, vol. 73, no. 3, pp. 285-290, 2001.

[18] R. Sánchez-Vioque, M. Polissiou, K. Astraka et al., "Polyphenol composition and antioxidant and metal chelating activities of the solid residues from the essential oil industry," Industrial Crops and Products, vol. 49, pp. 150-159, 2013.

[19] A. J. Isfahlan, A. Mahmoodzadeh, A. Hassanzadeh, R. Heidari, and R. Jamei, "Antioxidant and antiradical activities of phenolic extracts from Iranian almond (Prunus amygdalus L.) hulls and shells," Turkish Journal of Biology, vol. 34, no. 2, pp. 165-173, 2010.

[20] Y.-H. Jiang, X.-L. Jiang, P. Wang, and X.-K. Hu, "In vitro Antioxidant activities of water-soluble polysaccharides extracted from Isaria farinosa B05," Journal of Food Biochemistry, vol. 29, no. 3, pp. 323-335, 2005.

[21] F. Göğüş, H. Bozkurt, and S. Eren, "Kinetics of Maillard reactions between the major sugars and amino acids of boiled grape juice," LWT: Food Science and Technology, vol. 31, no. 2, pp. 196200, 1998.

[22] F. A. Tomās-Barberān and J. C. Espín, "Phenolic compounds and related enzymes as determinants of quality in fruits and vegetable," Journal of the Science of Food and Agriculture, vol. 81, pp. 853-876, 2001.

[23] J.-S. Kim, O.-J. Kang, and O.-C. Gweon, "Comparison of phenolic acids and flavonoids in black garlic at different thermal processing steps," Journal of Functional Foods, vol. 5, no. 1, pp. 80-86, 2013.

[24] M. Igual, E. García-Martínez, M. M. Camacho, and N. Martínez-Navarrete, "Changes in flavonoid content of grapefruit juice caused by thermal treatment and storage," Innovative Food Science and Emerging Technologies, vol. 12, no. 2, pp. 153162, 2011. 
[25] A. L. Dawidowicz, D. Wianowska, and M. Olszowy, "On practical problems in estimation of antioxidant activity of compounds by DPPH method (problems in estimation of antioxidant activity)," Food Chemistry, vol. 131, no. 3, pp. 1037-1043, 2012.

[26] C.-C. Wong, H.-B. Li, K.-W. Cheng, and F. Chen, "A systematic survey of antioxidant activity of 30 Chinese medicinal plants using the ferric reducing antioxidant power assay," Food Chemistry, vol. 97, no. 4, pp. 705-711, 2006.

[27] J.-S. Kim and Y.-S. Lee, "Antioxidant activity of Maillard reaction products derived from aqueous glucose/glycine, diglycine, and triglycine model systems as a function of heating time," Food Chemistry, vol. 116, no. 1, pp. 227-232, 2009.

[28] R. J. Watts, D. Washington, J. Howsawkeng, F. J. Loge, and A. L. Teel, "Comparative toxicity of hydrogen peroxide, hydroxyl radicals, and superoxide anion to Escherichia coli," Advances in Environmental Research, vol. 7, no. 4, pp. 961-968, 2003. 

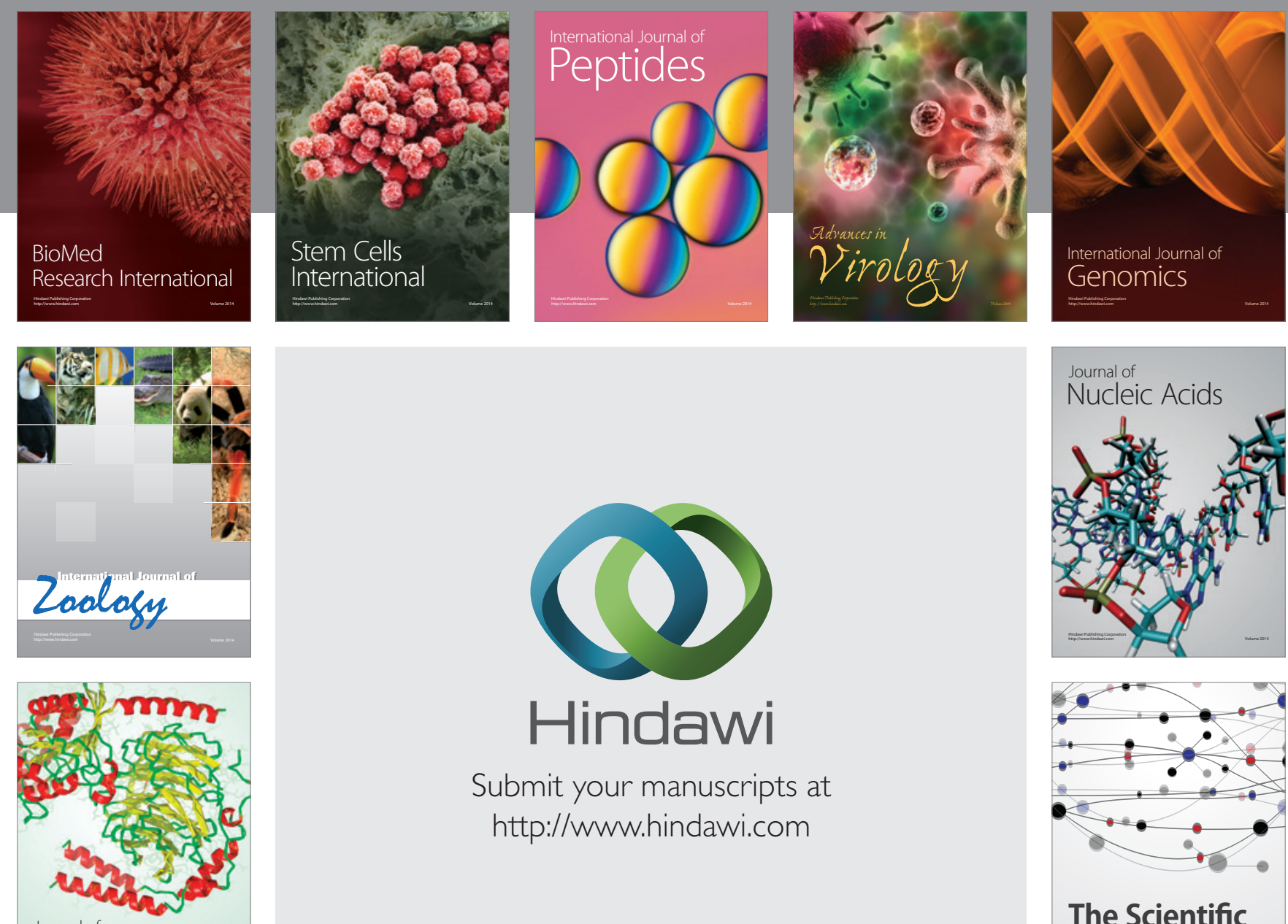

Submit your manuscripts at

http://www.hindawi.com

Journal of
Signal Transduction
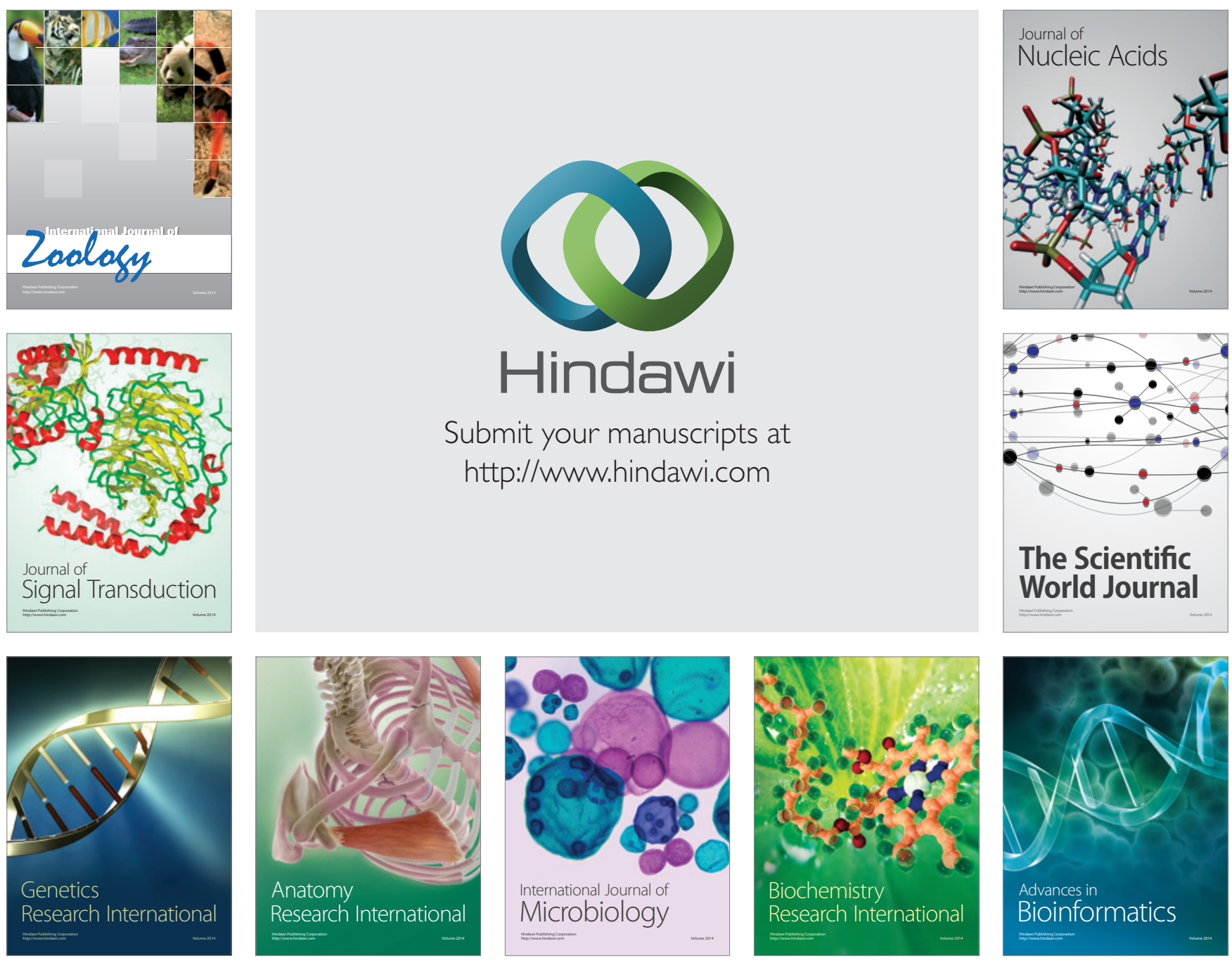

The Scientific World Journal
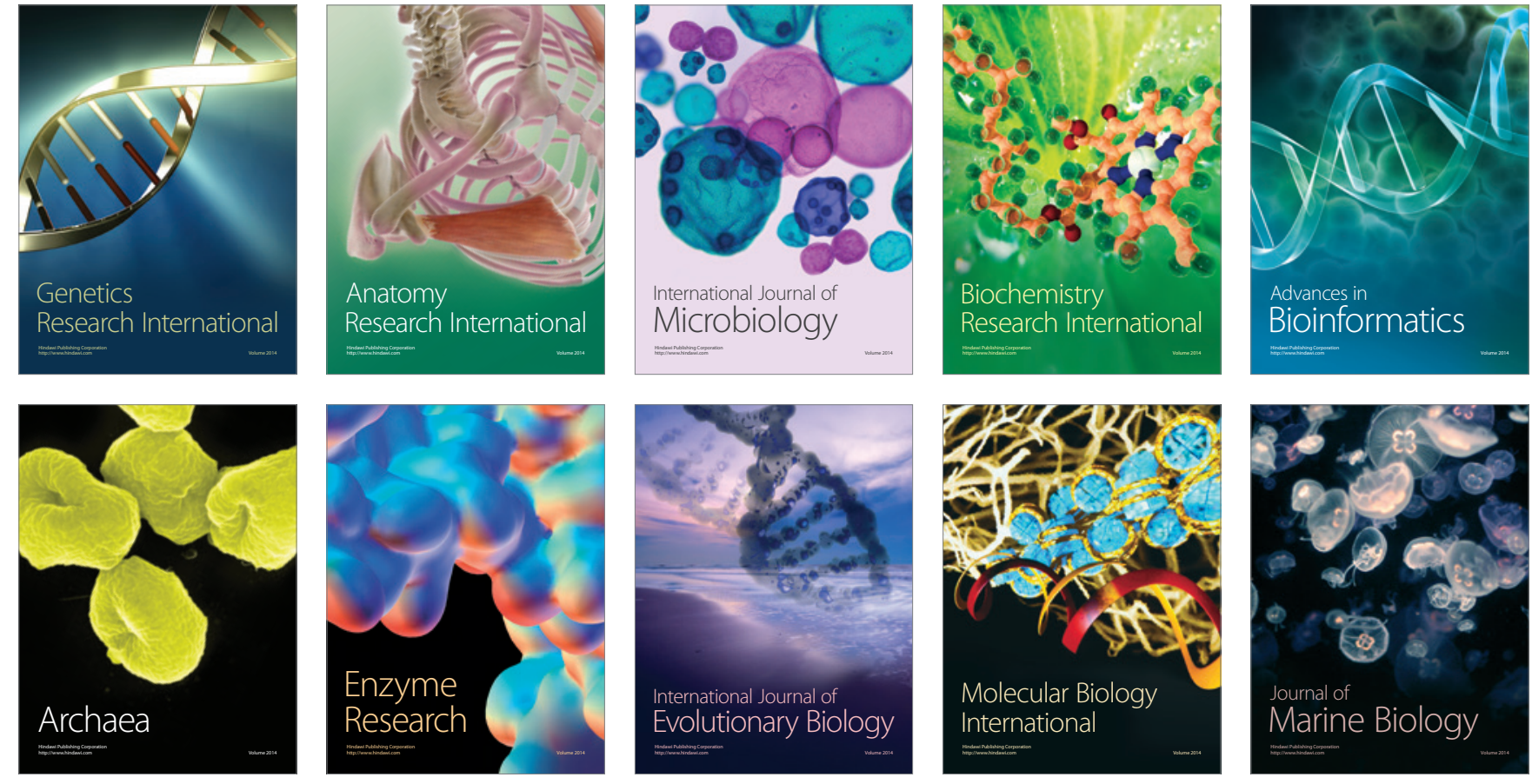